\title{
A CLINICAL STUDY OF PROPANIDID (FBA 1420)
}

\author{
J. E. Wynands, B.A., M.D., C.M., AND M. F. BuRfoot, M.A., B.M., B.CH."
}

\section{INTRODUCTION}

IN THE SEARCH for an ultra-short-acting intravendus anaesthetic agent with minimal post anaesthetic effects, several non-barbiturate drugs have recently been tried. Two, G29505 and Propanidid (FBA 1420), have been used extensively in clinical trials. This report is based on the clinical evaluation of the more successful of the two, Propanidid, in a series of 525 cases. Whereas previous reports emphasize the use of Propanidid as a sole anaesthetic agent,,2 this trial was undertaken to assess the value of the drug as an induction agent to general anaesthesia.

\section{Chemistry}

Propanidid is a derivative of eugenol and, therefore, has a similar structure to both G29505 and Propinal. It differs from them in having a propoxyacetyl radicle in place of the alkyl or allyl radicle ( $\mathbb{F i g} .1$ ). Physically, it is a pale yellow oil with a boiling point of $210-212^{\circ} \mathrm{C}$. For clinical use it is dissolved in 20 per cent Cremophor $\mathbb{E l}$, a non-ionized, surface-active aqueous solution of äthoxylated castor oil, to give a 5 per cent solution of Propanidid. This solution has a very high viscosity and is diluted with an equal volume of physiological saline for easier administration. Both 5 per cent and $2{ }^{\prime} / 2$ per cent solutions have been used. These solutions have a $\mathrm{pH}$, as measured by Astrup's technique of 4.1 and 4.6 respectively.

\section{Proponidid (F.B.A.1420)}
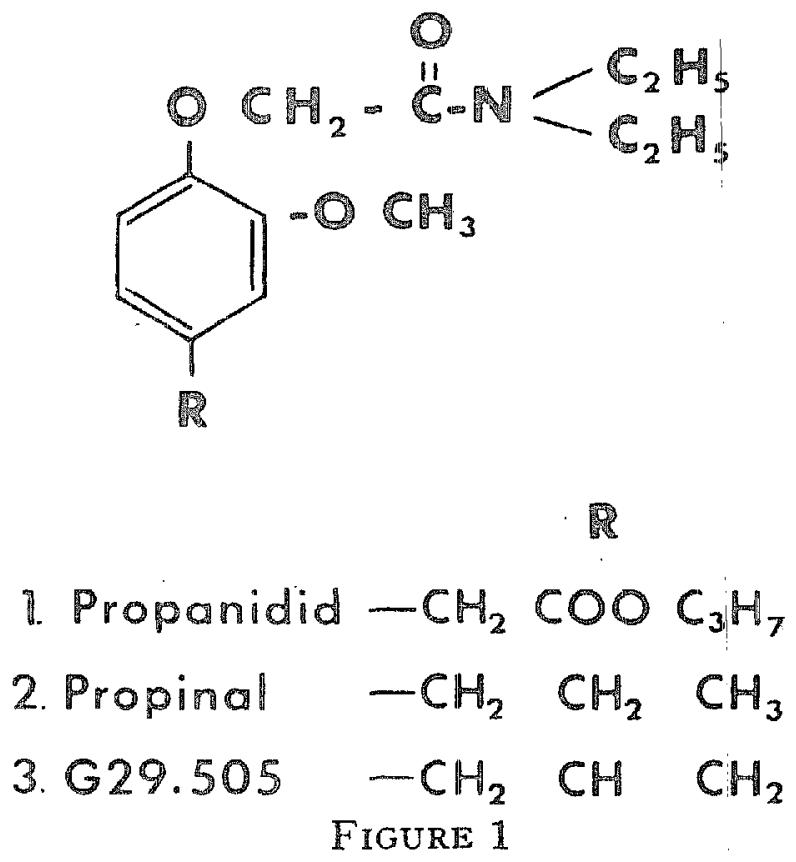

- Department of Anaesthesia, Royal Victoria Hospital, Montreal. 
Propanidid is rapidly metabolized by enzymatic splitting of the ester bond (Fig. 2), and this has been shown to occur mainly in the liver and to a lesser extent in the blood and kidneys. ${ }^{8}$ The resulting acid metabolite is anaesthetically inactive, and the extremely short duration of anaesthesia has been related to the speed of this breakdown. 8

\title{
Merabolism Of Propanidid
}

\author{
$\mathrm{CH}_{2}=\mathrm{C}=\mathrm{N}<\mathrm{C}_{2} \mathrm{H}_{5}$ \\ $\mathrm{Com}_{3}$ \\ Ester bond split by esterase in liver \\ blood and kidney.
}

Figure 2

\section{MeTHod}

Propanidid was administered to a series of patients undergoing a large variety of surgical operations (Table $\mathbb{I}$ ). The drug was given intravenously via an 18gauge needle in a dose range of from 3 to $13 \mathrm{mg}$. $/ \mathrm{kg}$. This wide dose range was soon narrowed when some experience had been gained with the drug, and the majority of patients received between 5 and $6 \mathrm{mg}$. $/ \mathrm{kg}$.

The duration of injection varied between 5 and 25 seconds, with an average of 12 seconds in the majority of cases. The patient was closely watched by two or three observers for five minutes immediately after the injection. During this time the pulse rate and blood pressure were recorded every minute and any changes in the respiratory pattern were noted. Reflex activily was tested by applying artery forceps to the skin, by observing the state of the pupils and their reaction to light, and by assessing the muscular tone of the limbs and abdomen by passive movement and palpation.

TABLE II

Site of Operation, 525 Cases

\begin{tabular}{lr}
\hline Extremities & 164 \\
Perineal & 105 \\
Abdominal & 76 \\
Head and neck & 66 \\
Trunk & 64 \\
lnguinal & 24 \\
Lung & 3 \\
Heart & 3 \\
Not recorded & 20 \\
Total & 525 \\
\hline
\end{tabular}


In a series of 25 patients, bromsulphthalein excretion studies were performed on the preoperative and first and third postoperative days. Lead II of the electrocardiogram was also recorded in these patients.

Propanidid was used in the majority of cases as an induction agent for general anaesthesia which was achieved using nitrous oxide, oxygen, and halothane administered by a face mask. Concentrations of 1 to 4 per cent halothane for 1 to 3 minutes were necessary to ensure an uneventful transition to inhalational anaesthesia.

A few patients having surgery under regional anaesthesia were given single doses of Propanidid to observe its effects uncomplicated by anaesthetic drugs. A few others were laryngoscoped and intubated without the use of muscle relaxants to assess the feasibility of this procedure.

Premedication consisted of appropriate doses of (1) pentobarbital, meperidine and atropine; (2) promethazine, meperidine and atropine; (3) meperidine and atropine; (4) atropine; or (5) nothing (Table II).

TABLE II

Effect of Premedication on Blood Pressure, 525 Cases

\begin{tabular}{|c|c|c|c|c|c|}
\hline B. P. fall $(\%)$ & $\begin{array}{c}\text { Pentobarbital } \\
\text { Demerol } \\
\text { Atropine }(\%)\end{array}$ & $\begin{array}{l}\text { Promethazine } \\
\text { Demerol } \\
\text { Atropine }(\%)\end{array}$ & $\begin{array}{c}\text { Demerol } \\
\text { Atropine }(\%)\end{array}$ & Atropine $(\%)$ & None $(\%)$ \\
\hline 0 or rise & 11 & 0 & 11 & 13 & 12 \\
\hline $1-9.9$ & 19 & 17 & 19 & 25 & 12 \\
\hline $10-19,9$ & 28 & 75 & 42 & 25 & 32 \\
\hline $20-290$ & 29 & 8 & 19 & 38. & 28 \\
\hline $30-39.9$ & 6 & 0 & 6 & 0 & 8 \\
\hline $40-49.9$ & 6 & (1) & 2 & 0 & 8 \\
\hline Over 50 & 1 & 0 & 0 & 0 & 0 \\
\hline
\end{tabular}

\section{RESULTS}

Central Nervous System

Induction time with Propanidid was short and uneventful. Patients who were given the drug intravenously in the arm were deeply asleep in from 20 to 30 seconds.

There was marked depression of reflex activity during the period of anaesthesia, which lasted from 4 to 8 minutes in unpremedicated patients. This depression was shown by the lack of reaction to light of the pupil; by the lack of response to painful cutaneous stimuli; and by the loss of pharyngeal, laryngeal, and tracheal reflexes. A laryngoscope could be inserted into the pharynx and an endotracheal tube passed into the trachea through the larynx.

Generalized muscular relaxation was moderate at the height of anaesthesia, as tested by passive movements of the limbs and palpation of the abdomen. Involuntary muscular acivity occurred in less than 6 per cent of all patients (Table III).

Following a single injection, recovery also was rapid and complete. Patients awoke within 4 to 8 minutes and were able to converse lucidly after a further 2 to 3 minutes. 
TABLE III

InCIDENCE OF Side-EFfects, 525 Cases

\begin{tabular}{lr}
\hline & Per cent \\
\hline Induction & 35 \\
Flushing of skin & 9 \\
Cough & 8 \\
Hiccough & 6 \\
Involuntary movement & \\
Postoperative & 30 \\
Nausea and vomiting & 8 \\
Headache & 4 \\
Phlebitis at injection site & \\
\hline
\end{tabular}

\section{Cardiovascular System}

Eighty-nine per cent of our patients had a fall in mean blood pressure (Fig. 3). Blood pressure in 60 per'cent of them fell by 10 to 30 per cent from preanaesthetic levels, and in 10 per cent of the patients falls were greater than this. Only 11 per cent showed no change or a rise in blood pressure. All periods of hypotension were transitory and the blood pressure returned to normal within 1 to 2 minutes except in those patients who were given halothane. Their blood pressure only partially returned to pre-anaesthetic levels.

Figure 4 shows the changes in pulse rate that occurred following the injection of Propanidid. Eighty per cent of the patients in our series had an increase in pulse rate varying in degree from 1 to 100 per cent. The distribution of these increases was completely random and apparently not related to any special event. It was also noted that the increase in pulse rate often preceded the fall in blood pressure.

No significant changes in Lead II of the electrocardiogram were encountered in the twenty-five cases where continuous tracings were recorded.

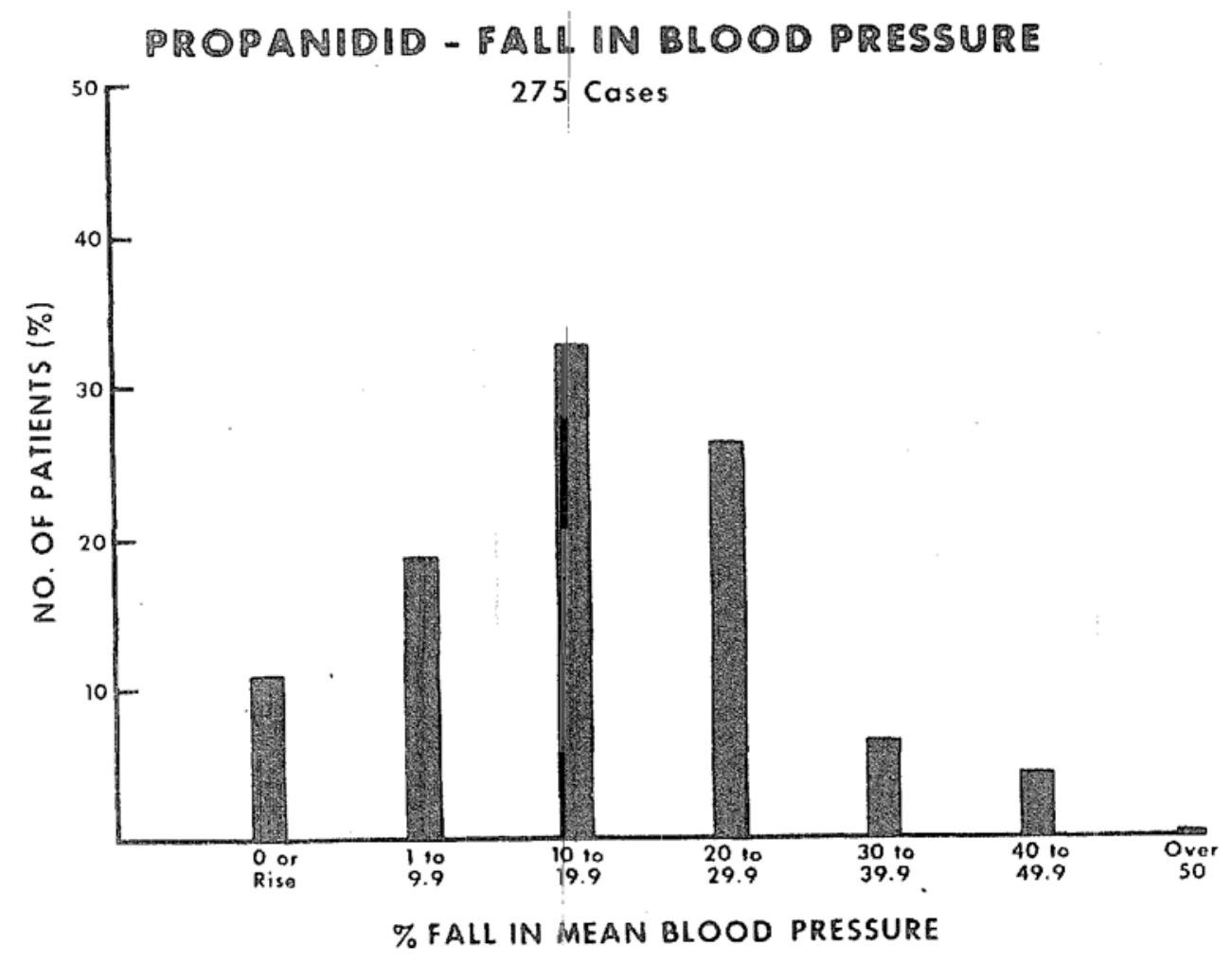

FIGURE 3 


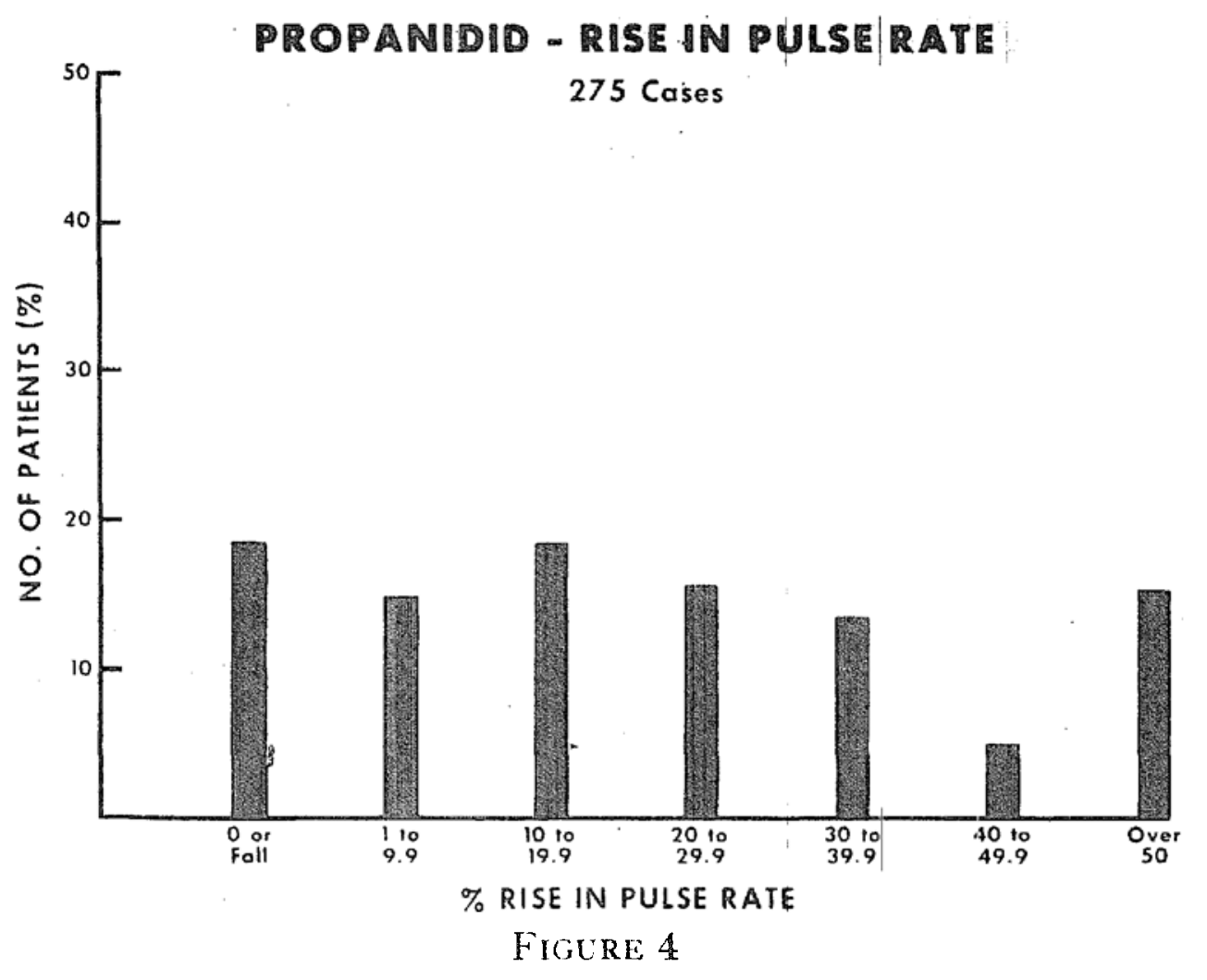

Premedication had no statistically significant effect on the fall in mean blood pressure or on the rise in pulse rate (Table II).

\section{Respiratory System}

Characteristic changes in the respiratory pattern similar to those described by Harnik ${ }^{6}$ occurred after the injection of Propanidid. The onset of anaesthesia was accompanied by a period of hyperventilation that lasted for approximately twenty seconds. This was followed by a period of hypoventilation that lasted up to thirty seconds, and in some cases ventilation ceased during this period of respiratory depression. During the period of hypoventilation it was easy to ventilate the lungs, and advantage was taken of this fact to introduce nitrous oxide, oxygen, and halothane anaesthesia.

\section{Metabolic}

The results of the bromsulphthalein excretion studies are shown in Table IV. Preoperatively, nine of twenty-five patients had greater than 5 per cent retention of bromsulphthalein at 45 minutes, compared with eighteen postoperatively:

\section{Complications}

The complications that were encountered are enumerated in Table III. On induction the most frequent side-effect was flushing of the skin, especially in

TABLE IV

Number of Patients with $>5$ Per Cent Retention of Bromsulphthalein at 45 MinUtes

\begin{tabular}{lcc} 
& No. of patients & $95 \%$ confidence limits $(\%)$ \\
\hline Preoperative & 9 & $19-59$ \\
Postoperative & 18 & $55-88$ \\
Total & 25 & \\
\hline
\end{tabular}


the blush areas. Troublesome side effects, cough, hiccough, and involuntary movements were seen in only a small proportion of cases. Cough (9\%), Hiccough $(8 \%)$, and involuntary movement $(6 \%)$ occurred in some cases in the same patient. Nausea with or without vomiting was the most frequently encountered side-effect in the postoperative period, occurring in 30 per cent of all patients given Propanidid. Other delayed side effects, such as headache (8\%) and phlebitis (4\%) were infrequent. The 4 per cent incidence of phlebitis at the injection. site includes those cases where intravenous fluids were administered for several days. No serious cases of thrombo-phlebitis were seen. In two cases where large doses of Phropanidid were accidently injected subcutaneously, a painless, slightly reddened swelling resulted, which disappeared spontaneously and completely during the next few days

\section{Discussion}

Our experience using Propanidid in over 525 cases shows this drug to be a useful ultra-short-acting induction agent from which patients recover within less than 10 minutes. The rapid rate of metabolism and the non-anaesthetic properties of the metabolites ensure absence of "hangover." It has few sideeffects and those encountered were of a minor nature. Obviously it is ideally suited to minor out-patient procedures, but it also has a place in longer surgery, supplemented with general anaesthesia, where rapid awakening is desirable.

Premedication with barbiturates and analgesics enhances the effects of Propanidid, ensuring a smooth transition into general anaesthesia in most cases, but delaying recovery. This emphasizes the extremely rapid rate at which Propanidid is metabolized.

In the face of the rapid clearance of Propanidid, a satisfactory general anaesthetic technique was achieved by injecting 5 to $6 \mathrm{mg}$. $/ \mathrm{kg}$. in approximately 10 to 15 seconds. As soon as hypernoea began, nitrous oxide, oxygen, and 1 to 4 per cent halothane were administered for 1 to 3 minutes, and thereafter the halothane concentration was lowered to normal maintenance levels. When apnoea occurred as a result of the Propanidid, the patient was ventilated until spontaneous respirations returned.

Although it was possible to intubate the trachea at the height of Propanidid anaesthesia without the use of muscle relaxants, we consider this procedure inadvisable because of the short duration of aetion of the drug and the violent reaction to the tube that may occur without warning, if for any reason general anaesthesia is not quickly achieved.

The alteration in cardiovascular dynamics encountered were not troublesome. Where marked hypotension occurred, it lasted for such a short time that the patients showed no adverse effects.

In those cases where there was some evidence of hepatic dysfunction postoperatively, it was thought that Propanidid was not responsible. The 95 per cent confidence limits of the number of patients showing a retention of bromsulphthalein greater than 5 per cent at 45 minutes preoperatively overlaps the same distribution postoperatively, and the difference is not statistically significant. In addition, 
patients with increased, retention of bromsulphthalein had all received other drugs known to cause such increased retention, and two of these were found to have biliary tract obstruction and liver disease at surgery.

The striking lack of complications at the site of injection is in marked/contrast to the"other eugenol derivatives used intravenously as anaesthetic agents. Those patients that did show some discolouration or induration at the injection site recovered without progression to severe thrombophlebitis. The local anaesthetic property of the drutg as reported by Howells ${ }^{2}$ accounts for the lack of discomfort in these instances.

The 30 per cent incidence of nausea with or without vomiting, although possibly due to Propanidid, may have been partially due to the other anaesthetic agents used and to the narcotics given for relief of pain on the ward.

The transitory flushing of the blush areas was thought to be due to a release of histamine. Cremophor $\mathrm{El}$ is known to do this in the dog. ${ }^{10}$ One could also speculate that the drop in blood pressure and the rise in pulse rate were also partially due to histamine release.

\section{SUMMARI}

Propanidid, a non-barbiturate, ultra-short-acting anaesthetic agent has been under clinical trial and the results of its use in 525 cases are presented.

In general it was found to be a useful and safe drug. Following a single injection of 5 to $6 \mathrm{mg} . / \mathrm{kg}$., patients fell asleep within thirty seconds and awoke in less than ten minutes. This rapid recovery necessitates prompt administration of further anaesthetic agents if surgery lasts longer than a few minutes. A satisfactory technique using Propanidid as an induction agent to inhalational anaesthesia is described.

\section{RÉSUMÉ}

Propanidid, un agent anaesthésique, non-barbiturique de trés courte durée, a été soumis à des essais cliniques et les résultats dans 525 cas sont présentés. En général, cet agent a été trouvé utile et sans complications. Après une seule injection endoveineuse de 5 à $6 \mathrm{mg}$. $/ \mathrm{kg}$., les patients furent endormis en trente secondes et se reveillairent en moins de dix minutes.

Dû à l'effet de courte durée, il faut administrer d'autres agents anesthésiques si l'intervention chirurgicale se prolonge plus de quelques minutes.

Une technique satisfaisante employant Propanidid comme agent d'jnduction est présentée.

\section{ACKNOWLEDGMENTS}

We are indebted to Dr. Werner Kober of $\mathbb{F B A}$ Pharmaceuticals Ltd., Montreal, for his cooperation in this study. We are also indebted to Miss Wilma Cinnamon, R.N., for her invaluable assistance in this project.

\section{REFERENCES}

1. Dundee, J. W. \& Clarke, R. S. J. Clinical Studies of Induction, Agents: IX. A Comparative Study of a New Eugenol Derivative, FBA 1420, with G29505 and Standard Barbiturates. Brit. J. Anaesth. 36: 100 (1964). 
2. Howells, T. H.; Odell, J. R.; Hawkins, T. J.; \& Steane, P. A. An Introduction to FBA 1420. Brit. J. Anaesth. 36: 295 (1964).

3. Goldman, V. \& KENNEDY, P. A Nop-Barbiturate Intravenous Anaesthetic. Anaesthesia 19: 424 (1964).

4. Dundee, J. W. \& Clarke, R. S. J. Alterations in Response to Somatic Pain Associated with Anaesthesia: XVII. Propanidid (FBA. 1420). Brit. J. Anaesth. 37: 121 (1965).

5. - Clinical Studies of Induction Agents: XII. The Influence of Some Premedicants on the Course and Sequelae of Propanidid Anaesthesia. Brit. J. Anaesth. 37:51 (1965):

6. HaRNicK, E. A Study of the Biphasic Venilatory Effects of Propanidid. Brit. J. Anaesth. $36: 655$ (1964).

7. Pallin, I. M. \& Lear, E. Acute Toxicity|Studies with FBA 1420 in 16 Mongrel Dogs. Reported by personal communication.

8. PytTER, J. The Enzymatic Breakdown of FBA 1420. Reported by pqrsonal communication.

9. Radnay, P. A. An Anaesthetic Agent for| the Out-Patient. Reported by personal communication.

10. Horatz, K.; Frex, R.; \& Zindler, M. Die intravenose Kurznarkose mit dem neuen Phenoxyessigsäurederivat Propanidid (Eppontol). Berlin: Springer Verlag (1965). 